Int. J. Odontostomat.,

7(3):395-400, 2013.

\title{
Intraosseous Hemangioma of the Mandible: Case Report and Review of the Literature
}

\author{
Hemangioma Intraóseo de la Mandíbula: \\ Presentación de un Caso y Revisión de la Literatura
}

Ilson Sepulveda*; María Loreto Spencer"; Enrique Platin"

SEPULVEDA, I.; SPENCER, M. L.; PLATIN, E.; TRUJILLO, I.; NOVOA, S. \& ULLOA, D. Intraosseous hemangioma of the mandible: case report and review of the literature. Int. J. Odontostomat., 7(3):395-400, 2013.

ABSTRACT: We report on a two year old female patient who presented with expansion to the left side of the ramus and body of the mandibule. Imaging studies revealed a lesion with characteristics suggestive of vascular origin. Histopathological analysis determined the presence of an intraosseous Hemangioma. Embolization guided angiography of the left external carotid artery was performed followed by surveillance to monitor regression of the lesion.

KEY WORDS: hemangioma, intraosseous, mandibular, TC, MRI, angiography.

\section{INTRODUCTION}

Vascular anomalies represent less than $1 \%$ of all bony tumors. Some authors believe a Hemangioma is a true neoplasm, while others claim that it is a hamartomatous lesion resulting from the intraosseous proliferation of mesodermal cells that undergo endothelial differentiation (Kondylidou-Sidira et al., 2012; Fernandez et al., 2003; Gómez Oliveira et al., 2008; Wu et al., 2011; Bonini et al., 2011). They appear mainly in soft tissue, although they also appear in hard tissue tissues more commonly in the head and neck, in approximately $50 \%$ of cases (Kondylidou-Sidira et al.; Eliot \& Castle, 2010; ; Gómez Oliveira et al.; Wu et al.; Naikmasue et al., 2010; Sakkas et al., 2007). It is the vascular tumor that occurs with the highest frequency in children while it recedes following the adolescent years (Aldridge et al., 2012; KondylidouSidira et al.; Fernandez et al.; Hansen et al., 2009; Naikmasue et al.; Sakkas et al.).

Intraosseous hemangioma was first described by Stanley in 1849 (Flis \& Connor, 2005), including central and peripheral intraosseous hemangiomas. The peripheral type originates in the vessels of the periosteum with a path of growth towards the medullary bone. On the other hand, central hemangioma originates in the medullary bone extending towards the bony cortex (Kondylidou-Sidira et al.; Bonini et al.). The latter is very rare and only comprises $1 \%$ of all intraosseous tumors (Aldridge et al.; Kondylidou-Sidira et al.; Fernandez et al.; Flis \& Connor; Gómez Oliveira et al.; Wu et al.; Bonini et al.; Robson, 2010). These lesions usually occupy the medullary cavity and less commonly affect the cortex, the periosteum and subperiosteal layers (Robson). The most common locations are the spine and the skull accounting for $75 \%$ of the cases. They are rare in the face (Bonini et al.; Sakkas et al.; Robson), and showed that they often present in the mandible and maxillary protuberances during their developmental years (Bonini et al.).

Intraosseous hemangiomas occur very rarely in the mandible (Kondylidou-Sidira et al.; Fernandez et al.; Flis \& Connor), and occur more frequently in the maxilla, mainly in the region of molars and premolars

* Oral, Maxillofacial, Head and Neck Radiologist, Otolaryngology Head and Neck Service, General Hospital of Concepcion, Faculty of Dentistry, Finis Terrae University, Santiago, Chile

* Medical Pathologist, Pathology Service. General Hospital of Concepcion, Concepcion, Chile

**** Professor of Oral and Maxillofacial Radiology, Faculty of Dentistry, University of North Carolina, Chapel Hill, North Carolina, USA.

Oral and Maxillofacial Surgeon; Neurosurgery Service; General Hospital of Concepcion, Concepcion, Chile.

*n*** Dental student.

${ }^{* *+* a * * *}$ Medicine student. 
(Kondylidou-Sidira et al.; Eliot \& Castle; Fernandez et al.; Gómez Oliveira et al.). Their incidence is higher in women than in men, with a ratio of 2:1, mainly between the second and third decade of life (Aldridge et al.; Kondylidou-Sidira et al.; Eliot \& Castle; Fernandez et al., 2003; Flis \& Connor; Wu et al.; Bonini et al.; Sakkas et al.; Robson). Other authors have described a higher prevalence in the fifth decade of life, maintaining the proportion according to sex (Kondylidou-Sidira et al.; Fernandez et al.; Gómez Oliveira et al.).

Clinically, the patient may be completely free of symptoms or may present with pain of variable intensity, soft tissue swelling, bluish color in the mucosa, tooth mobility, displacement of the mandibular canal, expansion of the cortices, deformity of the arch shape, resorption of roots, ageneses or accelerated dental exfoliation (Aldridge et al.; Kondylidou-Sidira et al.; Ching et al., 2009; Eliot \& Castle; Fernandez et al.; Flis \& Connor; Gómez Oliveira et al.; Wu et al.; Bonini et al.; Sakkas et al.).

Histologically, intraosseous hemangiomas are masses of endothelial cells that form vascular spaces of varying sizes mixed in a stroma of connective and fibrous tissue with visible trabecular bone observed in the thickness part of the lesion (Wu et al.; Flis \& Connor).

They can be divided into three groups according to the size of the vascular spaces: cavernous, the most common, capillary and mixed. The cavernous are composed of larger vessels and spaces covered by endothelium and scant stroma, capillaries are small vessels with pronounced cellularity and stroma. Mixed lesions show both capillary and cavernous characteristics (Kondylidou-Sidira et al.; Fernandez et al.; Gómez Oliveira et al.; Wu et al.). All present a proliferative stage characterized by rapid growth during the first years of life, with predominance in the vascularization, increase activity of endothelial cells and mast cells, followed by a regressive phase characterized by an increase in the fibroblastic matrix and a decrease of the vascular component (Aldridge et al.; Fernandez et al.; Hansen et al.).

Intraosseous hemangiomas have a variable radiographic appearance. In $50 \%$ of cases they present as multilocular ostelitic lesions with a "honeycomb or soap bubble appearance", with irregular and poorly defined borders (Aldridge et al.; Ching et al.; Eliot \& Castle; Fernandez et al.; Flis \& Connor; Wu et al.; Bonini et al.; Sakkas et al.; Robson).
The most commonly used radiographic examination to diagnose these lesions is panoramic radiography, computed tomography (CT), and magnetic resonance imaging (MRI) (Kondylidou-Sidira et al.; Eliot \& Castle; Flis \& Connor; Bonini et al.). In all of these imaging modalities hemangiomas in the proliferative stage, appear as a well-defined lobulated solid masses (Hansen et al.).

In CT, intraosseous hemangiomas often present as isodense masses in relation to the muscle and quickly change post contrast intravenous injection (IV) (Flis \& Connor; Hansen et al.). IV injection shows clear visualization of the cortical involvement and extent of the lesion (Kondylidou-Sidira et al.; Ching et al.; Flis \& Connor; Sakkas et al.). However, in MRI it appears as a moderately hyperintense mass on $\mathrm{T} 2$, increasing in intensity post contrast IV injection (Hansen et al.), showing its vascular involvement and its relationship with the adjacent soft tissues (Kondylidou-Sidira et al.; Eliot \& Castle; Bonini et al.).

(DSA) digital subtraction angiography allows the visualization of the main vessels that feed the lesion, playing an essential role in the differential diagnosis (Aldridge et al.; Ching et al.), which includes to the ameloblastoma, myxoma, cysts, odontogenic keratocyst and fibro-osseous lesions such as fibrous dysplasia (Ching et al.; Wu et al.; Bonini et al.).

Hemangiomas can be treated in an expectant manner; specifically in asymptomatic patients with minimal facial deformity (Kondylidou-Sidira et al.), anticipating their regression. If hemangiomas interfere with vital functions its regression can be accelerated thru medical therapies using steroids, alpha interferon or propranolol. The latter, is a new therapeutic option that has had permanent, satisfactory results with fewer adverse effects, favoring a decrease in the expression of the vascular endothelial growth factor (VEGF) and basic fibroblast growth factor (bFGF), causing apoptosis of endothelial cells, preventing growth and promoting the reduction of the size of the lesion more regularly than steroids (Hansen et al.; Kotrashetti et al., 2011).

In advanced cases that involve conditions, such as, facial disfigurement, repeated bleeding and palpable masses (Kondylidou-Sidira et al.; Kotrashetti et al.), alternatives therapies used include: laser, surgery, embolization and curettage (Aldridge et al.; KondylidouSidira et al.; Ching, et al.; Fernandez et al.; Hansen et al.; Wu et al. 2011). Radiotherapy is not considered as 
an alternative due to the damage it may cause to adjacent tissues and could result in malignization of the lesion. The treatment of choice is removal of the lesion with wide margins and ligation of the feeding vessels. Post surgery, these lesions have a good general prognosis and as long as the patient undergoes careful reconstruction and patients can regain optimal function (Kondylidou-Sidira et al.; Wu et al.).

\section{Clinical case}

A two-year-old patient presented to the ORL service for consultation with swelling to the left parotid area occurring over a one-year period. Blood and endocrinology studies were performed and were found to be within normal limits. CT and MRI imaging studies were obtained to assess the swelling area.

CT demonstrated the presence of an isodense multilocular expansive intraosseous lesion involving the left mandibular ramus and affecting the condylar area. The internal structure was heterogeneous in appearance and the normal bone trabeculate revealed a honeycomb appearance (Fig. 1A). Following contrast media injection, the lesion was highlighted revealing its large internal vascular areas but the CT did not show soft tissue or cervical adenopathies (Fig. 1B).

The MRI showed the left mandibular expansive process with high intensity signal on T2 (Fig. 2A), and regions of high intensity signal on $\mathrm{T} 1$ (Fig. 2B). These alterations in signal intensity are suggestive of a vascular component (Fig. 2C). There is no soft tissue involvement and post intravenous contrast, demonstrated a heterogeneous lesion (Fig. 2D).

Angiography demonstrates the lesion flow crucial in the decision to embolize left external carotid artery (Fig. 3), while an incisional biopsy is performed (Fig. 4).

\section{CONCLUSION}

Hemangiomas are vascular tumors more common occurring in children. Hemangiomas affecting the mandible are very rare, but are more common in the maxilla, mainly in the molars and premolars regions. Radiographically they present as a multilocular

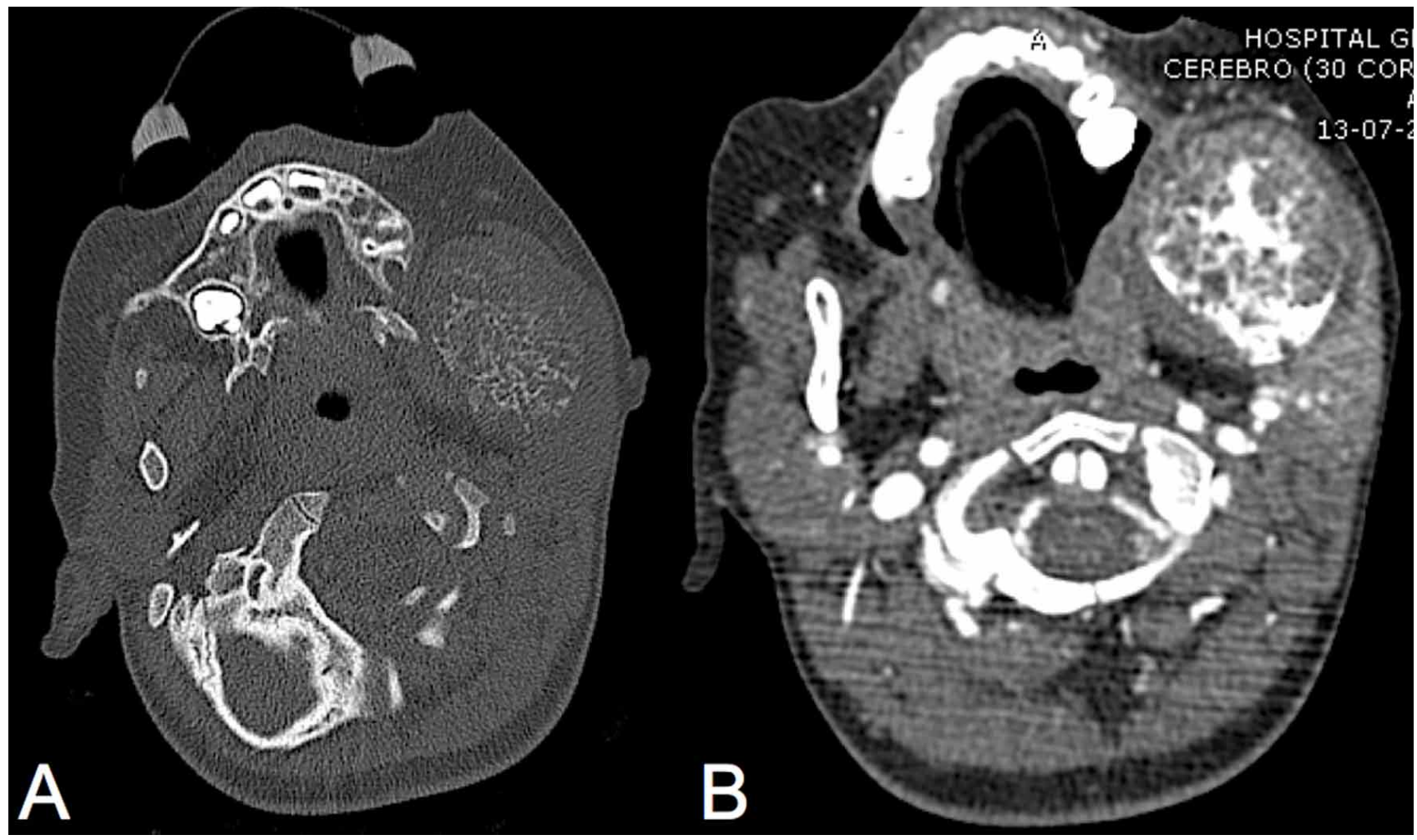

Fig. 1. A: CT bony window. Expansive lesion on the left side with honeycomb or bubble soap appearance. B: Post-intravenous injection of contrast media showing its multilocular appearance. 


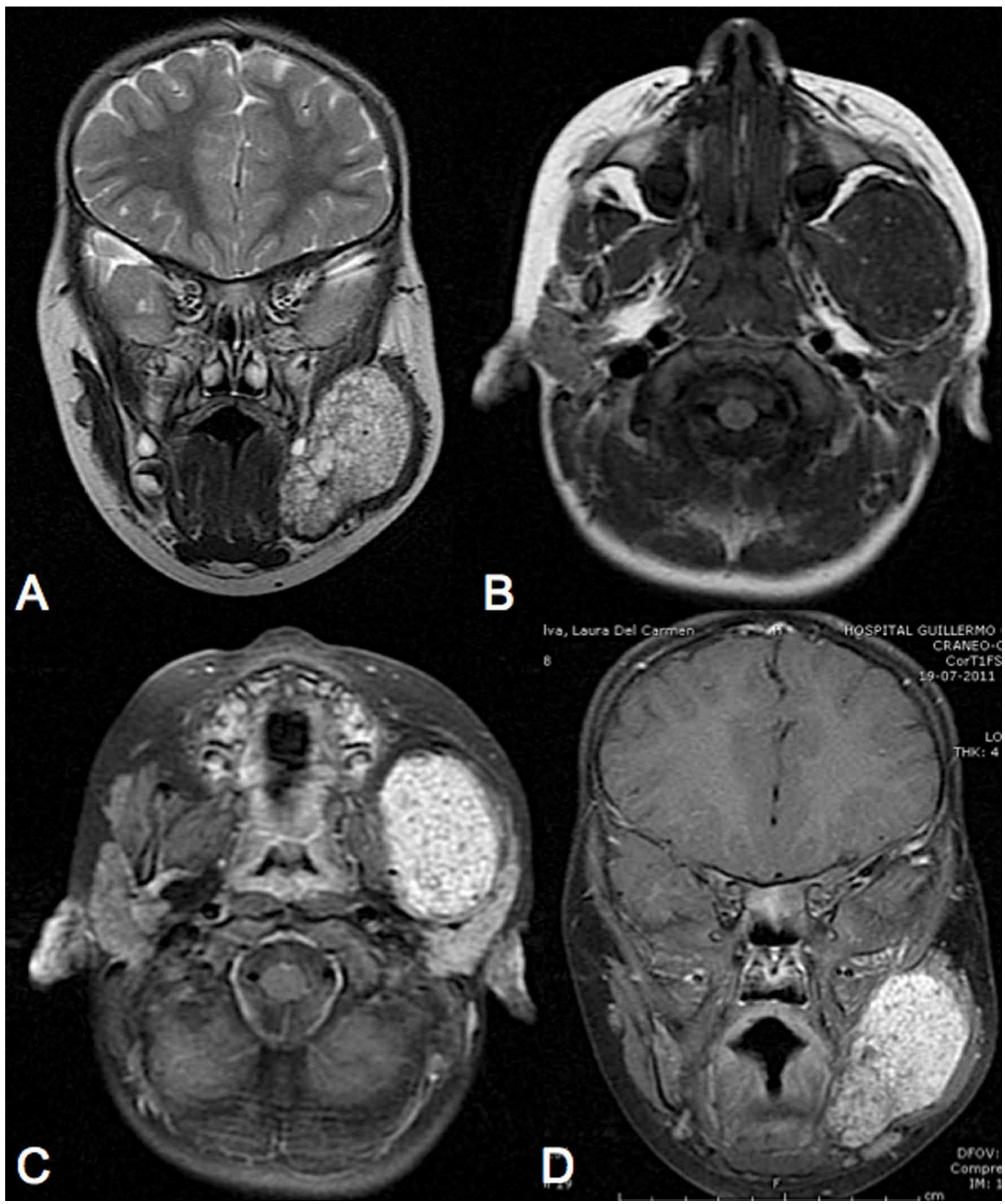

Fig. 2. A: T2 sequence showing a hyperintense area of the lesion. B: T1 sequence showing multiple hyperintense areas suggestive of vascular nature. C: T1 with magnetic contrast showing the contours of the lesion. D: T1 with magnetic contrast showing the expansive lesion displacing the adjacent soft tissue areas. 


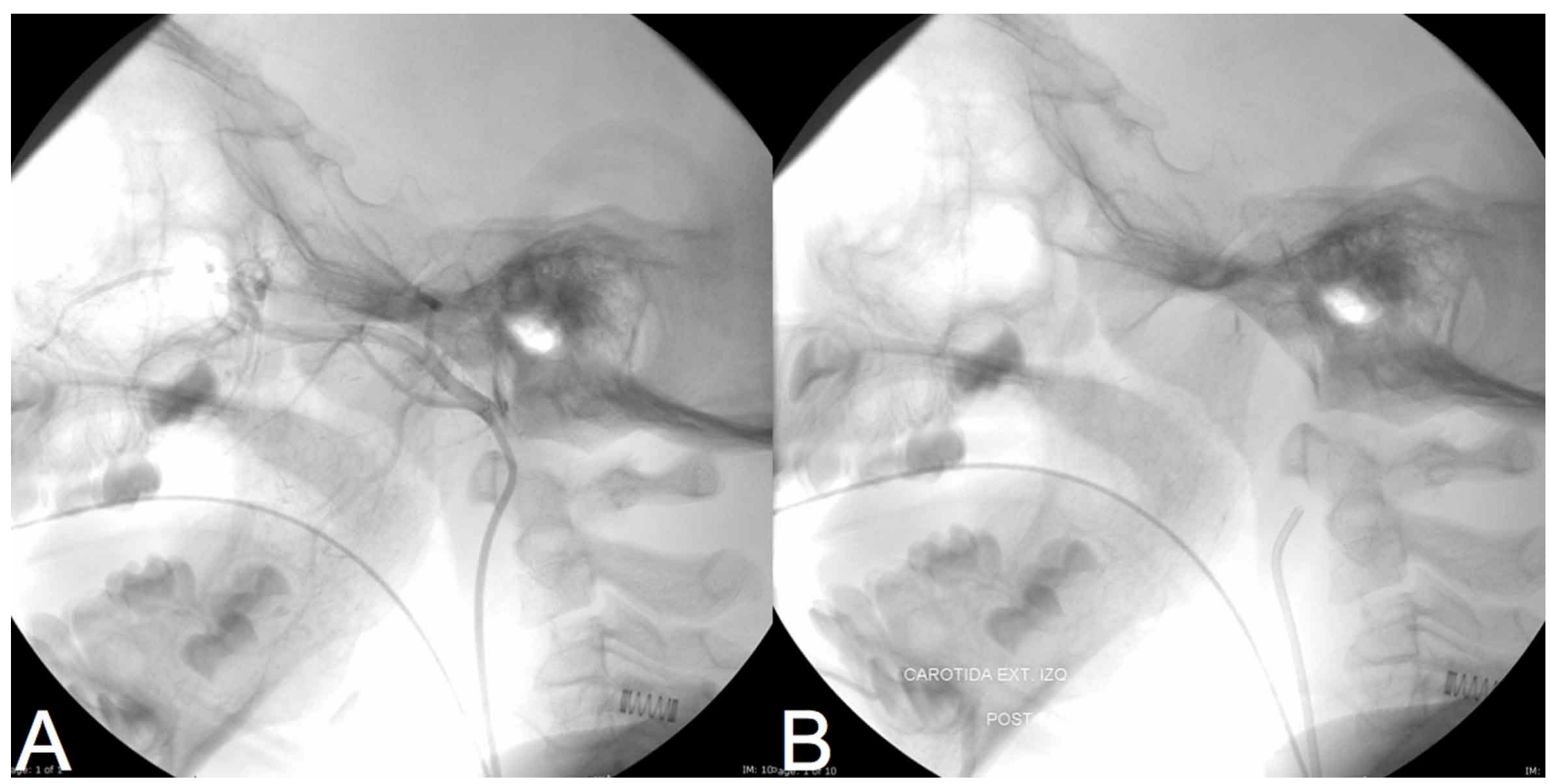

Fig.e 3. A: External carotid angiography pre-embolization. B: External carotid angiography post embolization.

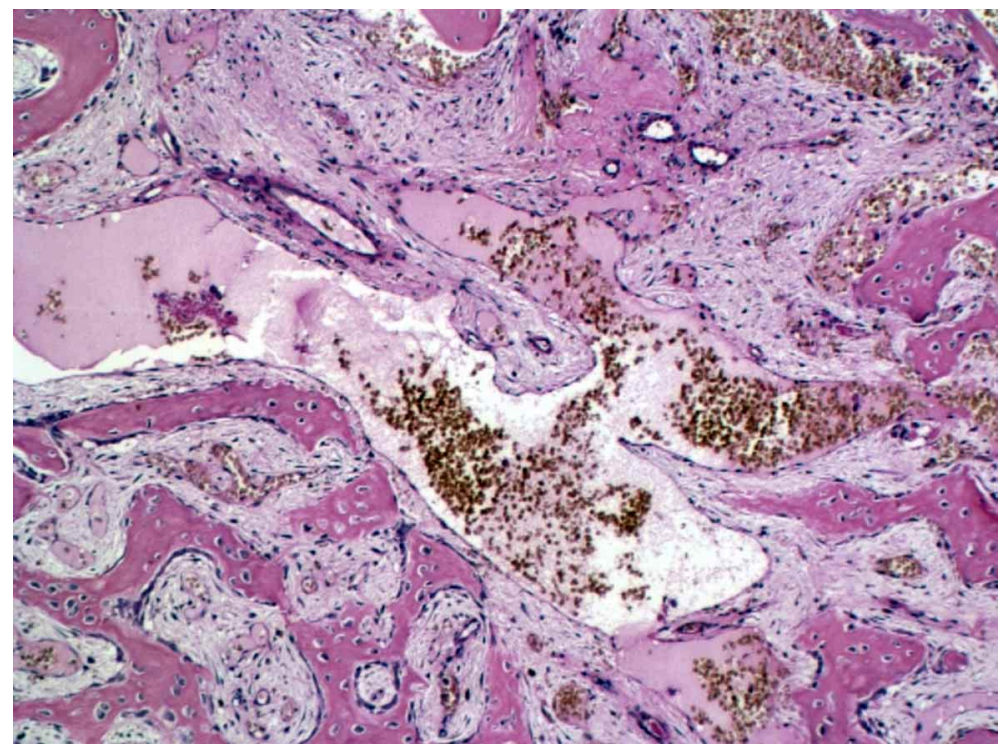

Fig. 4. Incisional biopsy of clinical case with $\mathrm{H}-\mathrm{E}$ stain.

osteolytic lesion with honeycomb or soap bubble appearance and irregular and poorly defined borders. In CT and MRI hemangiomas in proliferative stage, in their proliferative stage appear as solid, lobed masses, well delimited. Post contrast media injections allow a clear visualization of cortical involvement and the extent of the lesion. The treatment of choice is removal of the lesion with wide margins blood vessels ligation.
SEPULVEDA, I.; SPENCER, M. L.; PLATIN, E.; TRUJILLO, I.; NOVOA, S. \& ULLOA, D. Hemangioma intraóseo de la mandíbula: presentación de un caso y revisión de la literatura. Int. J. Odontostomat., 7(3):389-394, 2013.

RESUMEN: Se presenta en una paciente de sexo femenino de dos años que presentó expansión del lado izquierdo de la rama y cuerpo de la mandíbula. Los estudios de imágenes revelaron una lesión con características sugerentes a un origen vascular. El análisis histopatológico determinó la presencia de un hemangioma intraóseo. Se realizó la embolización guiada por angiografía de la arteria carótida externa izquierda junto y seguimiento de control para supervisar la regresión de la lesión.

PALABRAS CLAVE: hemangioma, intraóseo, mandibular, TC, resonancia magnética, angiografía. 


\section{REFERENCES}

Aldridge, E.; Cunningham, L. L. Jr.; Gal, T. J.; Yepes, J. F. \& Abadi, B. J. Intraosseous Venous Malformation of the Mandible: A Review on Interdisciplinary Differences in Diagnostic Nomenclature for Vascular Anomalies in Bone and Report of a Case. J. Oral Maxillofac. Surg., 70(2):331-9, 2012.

Bonini, F. K.; Bellodi, F. S. \& Souza, E. M. Propranolol treatment for hemangioma of infancy. An. Bras. Dermatol., 86(4):763-6, 2011.

Ching, B. C.; Wong, J. S.; Tan, M. H. \& Jara-Lazaro, A. R. The many faces of intraosseous haemangioma: a diagnostic headache. Singapore Med. J., 50(5):e195-8, 2009 .

Eliot, C. A. \& Castle, J. T. Intraosseous Hemangioma of the Anterior Mandible. Head Neck Pathol., 4(2):123-5, 2010.

Fernandez, L. R.; Luberti, R. F. \& Dominguez, F. V. Osseous maxillofacial radiographic aspects of hemangiomas: presentation of two cases and literature review. Med. Oral, 8:166-77, 2003.

Flis, C. M. \& Connor, S. E. Imaging of head and neck venous malformations. Eur. Radiol., 15(10):2185-93, 2005.

Gómez Oliveira, G.; García-Rozado, A. \& Luaces Rey, R. Intraosseous mandibular hemangioma. A case report and review of the literature. Med. Oral Patol. Oral Cir. Bucal, 13(8):E496-8, 2008.

Hansen, T.; Kunkel, M.; Katenkamp, D.; Eletr, S. \& Wagner, W. Hemangioma of the mandible: case report with special emphasis on bone degradation. Oral Maxillofac. Surg., 13(4):239-42, 2009.

Kondylidou-Sidira, A.; Dietrich, E. M.; Koloutsos, G.; Sakkas, L. \& Antoniades, K. Intraosseous vascular malformation of the mandibular condyle: Presentation of a case and differential diagnosis. Oral Radiol., 28(2):150-6, 2012.

Kotrashetti, S. M.; Urolagin, S. B.; Kale, T. P. \& Baliga, S. D. Central hemangioma-A case report and review of literature. Asian J. Oral Maxillofac. Surg., 23(1):46-9, 2011.

Naikmasue, V. G.; Sattur, A. P.; Burde, K.; Nandimath, K. R. \& Rai, T.A. Central hemangioma of the mandible: role of imaging in evaluation. Oral Radiol., 26:46-51, 2010.
Robson, C. D. Imaging of head and neck neoplasms in children. Pediatr. Radiol., 40(4):499-509, 2010.

Sakkas, N.; Schramm, A.; Metzger, M. C.; Berlis, A.; Schmelzeise, R.; Otten, J. E. \& Hohlweg-Majert, B. Arteriovenous malformation of the mandible: a life-threatening situation. Ann. Hematol., 86(6):40913, 2007.

Wu, J. H.; Du, J. K.; Lu, P. C. \& Chen, C. M. Interdisciplinary management of mandibular intraosseous haemagioma. Br. J. Oral Maxillofac. Surg., 49(7):e55-7, 2011.

Correspondence to:

Dr. Ilson Sepulveda

Otolaryngology, Head and Neck Surgery Service

General Hospital of Concepcion

San Martin Av. No 1436, Concepción

CHILE

Email: isepulvedaguilar@gmail.com

Received: 20-01-2013

Accepted: 26-08-2013 